\title{
Pathways to deliberative capacity: the role of the IPCC
}

\author{
Monika Berg $^{1}$ (D) $\cdot$ Rolf Lidskog $^{1}$
}

Received: 16 January 2017 / Accepted: 14 March 2018 / Published online: 30 March 2018

(C) The Author(s) 2018

\begin{abstract}
This article explores the arguments for expanding deliberation in the Intergovernmental Panel on Climate Change (IPCC) and scrutinizes their implications for the deliberative capacity of global environmental governance (GEG). An analysis of the IPCC is presented that builds on a systematic literature review and thus a broad set of scientific debates concerning the IPCC. Based on this analysis, two different paths are outlined, one moderate and one radical; these paths ascribe different democratizing functions to the IPCC and rely on different epistemologies. The moderate path emphasizes decision capacity, whereas the radical path strives to create deliberative space and to identify the value inherent in different claims. It is argued that the IPCC cannot accommodate the aspirations of these different pathways in a single assessment. Parallel assessments must be developed in complementary subject areas with different science-policy relations.
\end{abstract}

\section{Introduction}

The Intergovernmental Panel on Climate Change's (IPCC) main strategy is to enable political action by providing a scientifically established definition of the climate issue, including its consequences and measures for adaptation and mitigation. The work of the IPCC has been successful in terms of developing public awareness of the problem and putting climate change on the political agenda. Despite these contributions, it has proved to be a great challenge to reach global policy agreements and to stimulate sufficiently rapid and transformative changes in society. The exceptional position of the IPCC within climate science and in relation to the United Nations Framework Convention on Climate Change (UNFCCC) has yielded a large amount of wide-ranging research that scrutinizes the content of the IPCC's assessments, organization, and influence. Some analysts consider the IPCC a role model for the science-

Electronic supplementary material The online version of this article (https://doi.org/10.1007/s10584-0182180-8) contains supplementary material, which is available to authorized users.

Monika Berg

monika.berg@oru.se

1 Örebro University, Örebro, Sweden 
policy relations, while other analysts consider it partly responsible for the erosion of public trust in science (Haas and Stevens 2011, Jasanoff 2010, Wynne 2010).

A systematic review of the current literature shows that the IPCC's strategy, although it has been successful in putting climate change on the international political agenda, has also restricted the understanding of the problem and has downplayed the uncertainties, lack of knowledge, and unlikely, though possible, scenarios. ${ }^{1}$ This tendency of scientific framings to restrict debates in the political and public spheres by limiting the scope of deliberation is visible in many areas (in environmental and other fields), such as energy policy and biotechnology (Callon et al. 2009, Jasanoff 2012). To overcome this tendency, there are calls for more open, inclusive, and deliberative approaches to decision-making processes regarding global environmental matters (Beck et al. 2014). A particular problem is that many of these matters are fundamentally research-dependent, which has led to calls for a "democratized science" in which scientific assessments are more transparent for public evaluation and questioning and according to some proponents more inclusive of stakeholder perspectives (Berg and Lidskog 2017).

This paper explores the arguments for expanding deliberation in the IPCC and their potential impact on the deliberative capacity of global environmental governance (GEG). Accordingly, we systematically review and synthesize many findings concerning the IPCC and assess them from a deliberative systems perspective (Mansbridge et al. 2012). Based on this approach, this paper discusses how the IPCC can be (re)organized in order to increase the deliberative capacity of GEG. In assessing the existing research, we explore the extent to which - and the different ways in which - the IPCC could contribute to more open and deliberative GEG through its assessment work and recommendations to policy makers. Thus, we build on a broad body of research that tends to criticize the IPCC, but our main focus is to explore its potential.

In the next section, we present the deliberative systems approach, which emphasizes the interrelations among the different parts of a system and encourages the exploration of these parts' respective roles in enhancing deliberative capacity at the system level. The third section assesses the literature on the IPCC, and the central themes are inclusion, the role of consensus and certainty measures, and issue-framing in the knowledge-making process. In the fourth section, we present two different pathways for the IPCC. These pathways ascribe different democratizing functions to the IPCC and rely on different epistemologies. We argue that the IPCC may be unable to accommodate the aspirations of these different pathways in a single assessment. However, parallel assessments, with complementary subject areas and different science-policy relations, could be developed. In the last section, we identify key areas that merit further investigation to advance our understanding of how the deliberative capacity of GEG can be strengthened.

\section{Global environmental governance and the deliberative systems approach}

The call to democratize science is based on the crucial role that science plays in both defining environmental problems and in proposing strategies for their abatement, that is, the intrinsic relation between science and policy (Jasanoff 2012). Therefore, we argue that the meaning of a democratization of science needs to be understood and assessed in relation to its (potential)

\footnotetext{
${ }^{1}$ See the supplementary files for further information regarding the research review.
} 
role in democratizing GEG. For the democratization of global politics, deliberation may be the single most suitable practice because of the lack of democratic institutions and sovereignty at the international level (Dryzek 2006). The deliberative systems approach emphasizes that different parts of a system may have different democratic functions, such as empowered inclusion, collective will-formation, and collective decision capacity, and may strengthen different deliberative qualities, such as making the system more argumentative, open, equal, inclusive, or communicatively rational (Mansbridge et al. 2012, Warren 2012). This approach adopts a more relaxed stance toward the Habermasian "ideal speech situation," and it reconciles the tensions between different democratic theories, such as aggregative democracy, radical democracy, and deliberative democracy, by emphasizing their complementary roles in different parts of the system (cf. Moore 2017). In GEG, decisions must be made in different parts of the system through voting, while conflicting identities, interests, and subject positions are ever-present. However, the system's capacity for inclusive and authentic dialog, which is directed toward achieving mutual understanding, is essential to its democratization (cf. Baber and Barlett 2005). We conceptualize the democratization of GEG in terms of enhanced deliberative qualities that may have positive effects on the deliberative capacity of the entire system (Stevenson and Dryzek 2014). Under this conceptualization, the deliberative qualities of the scientific sphere, such as communicative rationality, may have a crucial role in democratizing GEG by strengthening its deliberative capacity (Dryzek 1990).

The central democratizing aspect of deliberation is the inclusion of multiple perspectives in a communicative and equitable manner (Mansbridge et al. 2012, p. 12). Different positions should be justified through argumentation and should aim to be generally accessible and mutually acceptable. The essential components of deliberative theory are thus inclusion and communicative equality and authenticity. Furthermore, it is crucial that deliberation aims for some type of shared agreement about how to move forward in order to enable decisionmaking. For a system to be considered deliberative, deliberative outcomes must become consequential at some point in the system (Parkinson 2012, Stevenson and Dryzek 2014). Each of these components is applicable to a systems perspective and to expert organizations such as the IPCC.

Inclusion may have different democratic motives. The legitimacy of a decision may depend on the inclusiveness of the decision-making process. However, the differentiation of modern society and the complexity of environmental problems necessitate an inclusive process not only for the intrinsic (democratic) value of this process but also to arrive at better decisions (Bohman 2006, Habermas 1996, Nowotny et al. 2001). Inclusion in science and in scientific assessments may be similarly motivated. A science that is inclusive of perspectives and research traditions has a greater ability to cope with increasingly complex empirical problems (Dryzek 1990, p. 191). From this perspective, what is crucial for deliberative capacity is not group- or interest-based representation but the inclusion of a multiplicity of perspectives, thus promoting quality deliberation and robust policy solutions (Bohman 2006). The inclusion of researchers with different backgrounds may thus be encouraged because it is favorable to a multiplicity of perspectives (Christiano 2012). Thus, the legitimacy of deliberation relies on its presentation of a greater breadth and variety of relevant knowledge and information (Elstub 2010, p 296). However, it is crucial to be attentive to who may represent a certain perspective and to what is lost in the process of translating and representing perspectives.

From a deliberative systems perspective, equal participation requires that no perspective, group, institution, or sphere completely dominates the process through which reasoning is presented (Thompson 2008: 504-5). For example, if science without other considerations was 
to determine policy action, this principle would be violated. However, it is not considered unproductive or unfair that some groups or institutions, such as science, have more influence than other groups. Such hierarchies may be democratically legitimate if they serve the public interest, for example, if disadvantaged groups are empowered and there are no hidden structures of domination (Brown 2015: 19). Enclave deliberation, such as narrow scientific debates, may be regarded as beneficial to the deliberative qualities of the entire system if such deliberation enables a group to articulate and develop its position and as long as this group is confronted with other perspectives in broader fora (Setälä 2014).

Regarding authenticity, such as the truthfulness, reliability, and justificatory character of claims, the scientific sphere possesses and fosters such qualities. Indeed, deliberation among specialists is often treated as exemplary by deliberative theorists (Moore 2017). However, the degree to which these qualities are transmitted to the rest of the system may vary (Berg and Lidskog 2017). For example, if an instrumentalist rationality dominates within the social sciences, values tend to be neutralized or reductively subsumed under economic values (Smith 2003). This reduction limits not only the scientific debate but also the ability of science to resolve complex policy issues, by extension limiting the communicative rationality of the public discourse (Dryzek 1990).

In terms of reaching agreements, the ideal of consensus has a salient although much debated role in deliberative democratic theory (Chambers 2003, Elstub 2010). The currently dominant view is a pragmatic one in which deliberation is judged as successful if people are willing to accept the decisions that result from it and continue to participate in it, which is sometimes referred to as meta-consensus (Elstub 2010, p 294). Note also that from a deliberative systems perspective, the task of joint agreement may not be ascribed to all system parts. The view of consensus has developed similarly in the scientific sphere. Consensus has generally been viewed as an indicator of scientific progress; however, the complexity of reality and the heterogeneity of the disciplinary, epistemological, and methodological approaches used to explore this reality make consensus difficult or even unproductive (Jasanoff 2012). Shared agreements on and understandings of an issue are seen as goals; therefore, consensus may be reached, not necessarily as the rational outcome of scientific practices but through negotiations, compromises and closure (Bijker et al. 2009). Similarly, consensus in assessments such as those of the IPCC does not necessarily occur on the level of substance and detail. This consensus is a joint acceptance based on the content and on the process of agreement (Moore 2017).

From a deliberative systems perspective, the IPCC may contribute to different democratic functions and strengthen different deliberative qualities. The role of the IPCC could be directed not only at "opening up" to include different perspectives based on different normative commitments, epistemological assumptions and views of society but also at "closing down" to facilitate decision capacity by speaking with a single voice. By drawing on a systematic review of the literature that addresses the IPCC and democratization (see the supplementary file on the methods), the following section assesses the motives for and manifestations of these functions in the assessment work of the IPCC.

\section{The IPCC's deliberative qualities}

The IPCC consists of a network of leading scientists who are appointed by governments and are employed by regular (and, most often, national) research organizations and who volunteer their 
time. The assessment reports undergo multiple rounds of drafting and review (by scientists and governmental representatives), and each assessment includes a summary for policy makers.

\subsection{Claims for broader inclusion}

Since its outset, the IPCC has become increasingly inclusive. It has expanded its scope with respect to geographical representation (in terms of countries), disciplinary representation (in terms of scientific areas), and its participatory practices (the aim and function of participation). The first type of inclusion that has concerned the IPCC is the inclusion of representatives of countries and regions in the assessment process. There is a clear and persistent overrepresentation of experts from OECD countries among the authors and reviewers of the assessment reports (Hulme and Mahony 2010, Ho-Lem et al. 2011). Nation states are more widely and equally represented through their direct influence on the final approval of IPCC documents, but this governmental influence is largely restricted to an influence on issues over which there is scientific dispute (Siebenhüner 2003). Thus, the space for this influence is heavily dependent on how consensus and scientific uncertainty are represented and approached in the assessment reports.

The dominating motive for broader representation is that the credibility and legitimacy of the IPCC require global representation and that without such representation, the reports may be rejected by parts of the world (Hulme and Mahony 2010, Siebenhüner 2003). Thus, the democratizing function that inclusion is intended to support is decision capacity. However, an additional argument for broader representation exists, namely, that misrepresentation biases the knowledge base toward certain epistemic traditions and thus also limits the scope of the assessment reports.

The inclusion of perspectives concerns the inclusion of different scientific fields and neglected sources of knowledge, such as indigenous knowledge (Beck et al. 2014, Ford et al. 2012). The IPCC's construction of the climate change knowledge base has been heavily biased toward the natural sciences in all its assessments (Hulme and Mahony 2010, IPCC 2017c). The social sciences remain marginalized, although many scholars have noted the potential of the social sciences to enhance our understanding of climate change, particularly its interrelation with social systems and human activity. It is maintained that scientific pluralism is beneficial to scientific progress and may reveal the influence of epistemological biases (Leuschner 2012), while restricted scientific inclusion may result in narrow framings of problems. Thus, both forms of inclusion (geographical and disciplinary representation) can be justified based on the deliberative advantages of including a multiplicity of perspectives that enable well-founded and multifaceted deliberation and that therefore lay the groundwork for better decisions.

The third aspect of inclusion that has concerned the IPCC relates to participation in the local and national implementation of climate change policies. Participatory practices of different types are an emerging, though still underdeveloped, perspective in the IPCC assessment reports (Aylett 2010). In the fourth assessment report (AR4), there is an emphasis on collaborative arrangements such as public-private partnerships, but there is little or no mention of how climate change adaptation can be linked to and benefit from existing participatory channels and communities at the local level (Aylett 2010). All the aspects of inclusion discussed above could be extended, to some degree, without challenging the way in which the IPCC is currently organized. However, the current format and logics of the IPCC restrict inclusion because of the role that consensus has come to play. 


\subsection{Contested consensus}

One of the most dominant themes in the debate regarding the IPCC concerns its consensus process and treatment of uncertainties. This emphasis is understandable, since "speaking consensus to power" has been the dominant interpretation of the IPCC's role in GEG (Van der Sluijs 2012: 179, see also Beck 2011). In the traditional linear understanding of sciencepolicy relations that has come to shape the IPCC, scientific consensus is regarded as a prerequisite to decision-making. "Speaking consensus to power" is intended to make science relevant to policy, provide a firm foundation for policy making and thus bolster the legitimacy of both spheres (Van der Sluijs 2012: 179, see also Beck 2011, Lidskog and Sundqvist 2015). Even when the consensus view and the process that leads to it have been questioned (e.g., Climategate, which uncovered errors in AR4), the response has been to strengthen this model, obtain external evaluations, and specify and better communicate the uncertainties in the current, presented state of knowledge (Van der Sluijs 2012: 190).

The consensus approach has been criticized. Two main criticisms illustrate the mechanisms by which the consensus approach affects and limits the scope of the assessments and, therefore, the grounds for deliberation. First, the consensus model favors a single framing of the issue. The dominant frame governing the work of the IPCC is based on the global average temperature as a risk indicator, which has restricted the assessments and political discussions of climate change (Beck et al. 2014: 81) and likely also the knowledge base through what research that is funded and conducted. A narrow and scientific framing of the problem limits the solutions that can be identified and restricts (or even eliminates) policy options and debate (Van der Sluijs et al. 2010). For example, the relation between possible reforms in the financial sector and necessary investments in the global shift to renewable energies remains poorly assessed and discussed (Carnicer and Peñuelas 2012). However, such restriction of deliberative space may be attempted - and necessary - if a global agreement is desired because consensus necessitates a common and strictly delimited ground for deliberation.

Second, the consensus approach may cause climate risks to be portrayed as less severe than they really are. This inaccuracy is partly due to the restricted representation of the climate problem, which determines the scientific knowledge considered relevant and worthy of attention (Curry 2011: 724). Other mechanisms are also at play. The pressure to (re)establish the legitimacy of climate science leads to closer scrutiny of arguments that support climate change than arguments that deny it (Freudenburg and Muselli 2013). Weak signals of a possible environmental catastrophe and matters on which consensus cannot be reached receive less attention than they deserve, even when they are important to policy makers (Wynne 2010, Van der Sluijs 2012). Lack of knowledge is not meaningfully addressed in the assessments, which leads to overconfidence regarding what we do know (Curry 2011, Swart et al. 2009). Altogether, this criticism means that the deliberative basis that science provides for the policy sphere is shaped and restricted by the consensus principle in such a way that climate risks are downplayed.

There is also a debate over whether scientific consensus is needed for policy decisions (see Grundmann 2006 and Haas and Stevens 2011, for opposing views). In contrast to the dominant understanding that has come to inform the IPCC, an alternative, pragmatic knowledge view has begun to emerge that does not consider scientific consensus to be crucial. It emphasizes the need for a plurality of perspectives and an enlarged deliberative space. This view argues that if political action is not perceived as dependent on scientifically established predictions of the problem, less research focusing on long-term anthropogenic changes in climate would be 
required. This would create space for a greater variety of perspectives, including more policyfocused research that may stimulate deliberation regarding alternative representations of climate change and alternative policy options (Beck 2011). A greater focus on understanding and managing short-term relations between climate and society would disrupt the dominance of abstract and generalized knowledge and create space for contextualized and place-related knowledge (Beck 2011).

There is a dislocation between the global scientific framing of climate change and how it is publicly evaluated at national and local levels (Jasanoff 2010). The scientific framing of the issue, together with the economistic framing of the appropriate responses, restricts the understanding of the problem in a way that excludes other values. These framings may thus alienate the public and prevent collectives around the world from taking responsibility for climate change (Wynne 2010:291). Such framings may also prevent an exploration of climate change's significance with respect to how we think about ourselves and our societies (Hulme 2009). Informed contextualized deliberation that incorporates ethical and value dimensions is essential. The uncertainty that surrounds climate change, both scientifically and politically, includes ethical contestation and radical doubt (Friedrichs 2011: 471). These dimensions are crucial for understanding how climate change can be mitigated, and the social sciences have much to contribute in this regard.

\section{Choosing a path}

These debates and contributions lay the foundation for a rather elaborate picture of the deliberative qualities and limitations of the IPCC and their potential effects on the deliberative capacity of GEG. Two different paths are traceable: one implies moderate and one more radical changes (see Table 1). The implications of these different paths for GEG are developed and explored by drawing on deliberative systems theory. We position the strategies of the IPCC in relation to these two paths and identify possible amendments that incorporate lessons from both paths.

The moderate path stems from a rationalistic knowledge view in which truth-finding is at the center and deliberation mainly pertains to how to solve the problem. This path serves to reappraise the distinction and division of labor between the scientific sphere and the policy sphere (Sundqvist et al. 2015). The effects sought through extended inclusion are primarily focused in the scientific sphere in terms of providing a broader foundation for the IPCC assessments. However, these effects are also intended to extend beyond the scientific sphere, because broader inclusion is intended to lend credibility to the work and conclusions of the IPCC and, therefore, to its policy advice and to the climate issue (as framed by the IPCC).

Thus, the necessary "democratization" is confined to the inclusion of "relevant" knowledge for accuracy and to the transparency of IPCC assessment reports. The primary democratic function in relation to GEG is to facilitate collective decision capacity by establishing the problem and strengthening its position on the political agenda through its epistemic authority. The IPCC should influence collective will-formation through the transmission of expert knowledge. It is inherent to the logic of this path that it attempts to restrict the deliberative space of the policy sphere, which is seen as necessary for political decisions and actions. Thus, science contributes to closing down deliberation, which facilitates political decision-making.

The direction of the IPCC is in many respects compatible with the moderate path. The IPCC strives to speak on behalf of global science with a unified voice to achieve epistemic 
Table 1 Two democratizing pathways for the IPCC

\begin{tabular}{|c|c|c|}
\hline & Moderate (path-bound) & Radical (path-breaking) \\
\hline Inclusion & $\begin{array}{l}\text { Inclusion of groups and perspectives to } \\
\text { increase legitimacy and to broaden } \\
\text { the knowledge base }\end{array}$ & $\begin{array}{l}\text { Broader inclusion of perspectives and } \\
\text { framings of the problem }\end{array}$ \\
\hline Equality in the process & $\begin{array}{l}\text { The scientific sphere has a dominant } \\
\text { position in the justificatory process }\end{array}$ & $\begin{array}{l}\text { A more inclusive and reflexive scientific } \\
\text { sphere provides the foundation for, and } \\
\text { contributes to, deliberation } \\
\text { Enables more diverse, contextualized and } \\
\text { localized deliberations and actions }\end{array}$ \\
\hline Consensus & $\begin{array}{l}\text { Arrived at within the scientific sphere } \\
\text { and approved by the policy sphere }\end{array}$ & $\begin{array}{l}\text { Abandonment of the consensus principle } \\
\text { Focus on alternative perspectives to create } \\
\text { enlarged space for deliberation and action }\end{array}$ \\
\hline Science-policy relation & Linear & Intertwined and iterative \\
\hline Legitimacy of the process & $\begin{array}{l}\text { Based on restricted (scientistic) episte- } \\
\text { mic authority, which lends legiti- } \\
\text { macy to policy }\end{array}$ & $\begin{array}{l}\text { Based on deliberative authority (inclusion } \\
\text { of perspectives; stimulation of } \\
\text { argumentation and dialog; more } \\
\text { explicit value judgments) }\end{array}$ \\
\hline $\begin{array}{l}\text { Main democratizing } \\
\text { function }\end{array}$ & $\begin{array}{l}\text { Enabling collective decision capacity } \\
\text { by settling the issue scientifically }\end{array}$ & $\begin{array}{l}\text { Empowered inclusion through the } \\
\text { inclusion of different perspectives and } \\
\text { alternatives } \\
\text { Collective will-formation through more ex- } \\
\text { plicit value positions and considerations }\end{array}$ \\
\hline
\end{tabular}

authority in matters of climate change and climate policy (Beck et al. 2014). When the legitimacy of the IPCC was challenged by "Climategate" (an incident in which email conversations among climate scientists became public and cast doubt on their reputation and the reputation of the IPCC), the IPCC's response was to increase accountability through an external review and transparency through communication. However, it simultaneously strengthened its linear model of expertise (Beck 2012).

The IPCC has responded to appeals for broader inclusion. For example, the current chair of the IPCC, Hoesung Lee, stated in the call for nominations of authors for the AR6, "We are seeking scientists with expertise across the disciplines assessed by the IPCC. /.../ We also hope that more scientists from developing countries and more women scientists will be nominated as IPCC authors to give us diverse author teams that can provide a range of relevant perspectives" (IPCC 2017a). This inclusiveness is moderate because of its motivation, namely, accuracy and bias elimination. Importantly, from a deliberative systems perspective, closed deliberation within expert communities may be encouraged if it is challenged by other perspectives in a broader setting, which is certainly the case with climate science and the assessment reports.

Rather than emphasizing the distinctions between science and policy, the constructivist proponents of the radical path acknowledge the inherently interpretive nature of facts. By emphasizing the fundamental contingency of facts and acknowledging "uncertainty and dissent as facts of life" (Van der Sluijs 2012: 187), this path strives toward a systematic exploration of different problem framings, options, and perspectives instead of pursuing the current search for $a$ proxy for truth (Edenhofer and Kowarsch 2015). A broader set of systematically explored and transparently argued directions not only facilitates and informs constructive policy deliberation but also implies an extended space for action. Thus, the aim is not to delimit deliberative space through consensus but to provide a more multifaceted 
knowledge foundation that can stimulate more diversified authentic deliberation and agreement and action in different settings. The primary democratizing function of the moderate path is decision capacity, whereas for the radical path, it is enhanced deliberative capacity and empowered inclusion. Through the inclusion of different perspectives and alternatives and the embracing of contextualized knowledge, the radical path enables and provides the foundation for authentic deliberation based on a broader set of claims and frames in both the scientific and in the policy and public spheres.

Importantly, we here touch upon a crucial difference in the assumptions of the two pathways regarding how action is stimulated. The moderate path assumes that scientific progress and consensus enable policy action and that multifaceted and undecided scientific debate impede negotiation and action. The radical path, in contrast, argues that the consensus strategy results in a narrow range for action and that broader debate stimulates a more diverse set of actions as well as more radical, path-breaking alternatives.

By accommodating a broader set of perspectives, proponents of the radical path seek to emphasize the social processes and society-nature relations that have instigated climate change. The problem definition offered by the IPCC remains natural scientific, since the assessment of the problem of climate change is centered on its expressions in nature. A possible way forward is to complement the IPCC's assessment reports with a working group on the social science basis of climate change (comparable to its current working group I on the physical science basis of climate change). This working group should have the specific aim of assessing the social processes that drive anthropogenic climate change. Such a working group would have the benefit of engaging a broad set of perspectives higher up in the problem defining process (cf. Nowotny et al. 2001, Berg and Lidskog 2017). Currently, the inclusion of other bodies of knowledge in the IPCC, such as gray literature and indigenous and local knowledge, is mainly intended to increase adaptive capacity or to compensate where scientific information is lacking.

However, even with its natural scientific framing of climate change, the IPCC's engagement with national representatives is challenging. The national political representatives of the panel may object to wording that could assign blame or responsibility (see Moore 2017). As is discussed further below, a multiplicity of perspectives and a more interpretive epistemology reveals the values inherent in current societal processes and knowledge claims. For the IPCC's assessment reports, this would probably render impossible the line-by-line agreement of nation states that currently gives the assessment its status as a policy prescriptive document (see, e.g., the dissatisfaction of a policy maker with part of the assessment of the social science literature in AR5 in IPCC 2017: 33). Adjustments toward the radical path therefore imply the need to divide the work of the IPCC into several more diverse knowledge assessments rather than focusing on the production of one large assessment (Beck et al. 2014). It would be necessary for the science-policy relation to differ among assessments in order to assert the current benefits of establishing the natural state of climate change. Crucially, each assessment should have clear implications for the content of the other assessments to allow the knowledge of causes to stimulate the assessments on adaptation. To the extent that the needed solutions are social— not just technical — they must derive from a social science problem assessment.

An additional democratizing function of the radical path is the generation and stimulation of more explicit value dimensions and the consideration of their limitations on different knowledge claims (Edenhofer and Kowarsch 2015: 61). An openness to different value dimensions may stimulate debate in the public sphere and enable collective will-formation. A recognition of the value dimensions of facts (Fischer 2003) and problem definitions (Stone 2012) would 
illuminate the tendency in both policy and research to reduce environmental and social values to economic values (Hulme 2009; Smith 2003). It could also stimulate reflexive consideration of aspects such as nature, progress, or human-nature relations, which could stimulate new imaginaries and personal and collective identities (Baber and Bartlett 2005; Hulme 2009).

However, accommodating different fundamental values that guide the understanding of human-nature relations is a serious challenge. The ambition of the Intergovernmental SciencePolicy Platform on Biodiversity and Ecosystem Services (IPBES) to review and assess different types of knowledge is an illustrative example. The assessment of scientific literature - which the IPCC performs - implies a need to accommodate different epistemologies. With the inclusion of non-scientific knowledge in assessments - which the IPBES strives to accomplish — not only epistemological differences but also ontological differences arise; fundamental, diverging understandings of the constitution of reality must therefore be bridged (Löfmarck and Lidskog 2017). The IPBES has addressed this difficulty by developing an approach whereby scientific knowledge and indigenous knowledge are presented simultaneously, as a "Rosetta stone for biodiversity" (Diaz et al. 2015). Placing different ontological perspectives side by side emphasizes that fundamentally different ways of understanding and valuing biodiversity are at play, which may stimulate value judgements and debates. IPBES has come relatively far in its systematic inclusion of diverse knowledge-holding communities and stakeholders. However, giving different world-views and their claims weight in the assessments without allowing one to have dominance over the others is indeed an institutional and intellectual challenge (Esguerra et al. 2017; Montana 2017; Turnhout et al., 2016). The ambition is to create synergies between differing knowledge systems, to generate an enriched knowledge base, with benefit for all involved knowledge systems (Díaz et al. 2015). So far we have only witnessed the first steps toward such an achievement.

The radical path attempts to make the existing interrelation between the scientific sphere and the policy sphere more dynamic, explicit, and transparent. Softening the boundaries between the different spheres may serve to merge the deliberation in different spheres (scientific, policy, and public) and therefore extend the reach of the deliberative capacities of the scientific sphere. Social scientists play the crucial role of attentively translating the positions that have been adopted by individuals or groups into the dispassionate language of social science and deliberative processes, and scientists play the crucial role of translating scientific findings into ordinary language and offering public-oriented reasons to support their recommendations (Baber and Bartlett 2005). Notably, in these roles, the authoritative position still belongs to trained scientists and the scientific discourse.

For the radical path to be truly radical, the authority of science must be renegotiated; the exclusive position of science can no longer be relied on as a principle. The authority of science must be continuously enacted deliberatively (Hajer 2012). From a deliberative perspective, the authority of science need not be epistemic in a restricted scientific sense; instead, it could be derived from the unique and systematic qualities of science in contributing to reliable, argumentative dialog and aiming for mutually acceptable positions. The assessment of claims would be based on communicative and pragmatic validity (Kvale 1995). Thus, the radical path necessitates a shift in the understanding of what constitutes epistemic authority from a more restricted view (belief in science) toward an authority based on deliberative qualities.

Indeed, the internal work of the IPCC is much more deliberative than the external image suggests (Moore 2017). During the assessment work, researchers aim to achieve a mutually acceptable description of the current "state of the art" of climate change research and to gain the acceptance of national policy representatives, which is in many respects a deliberative 
process. However, the moderate and radical paths oppose one another in terms of whether such deliberation should be handled internally or whether this process should be even more transparent so that these deliberative and reflexive qualities can expand to the broader system.

Finally, a recurring critique of the radical path is that it aims to expand the deliberative space but does not consider how the process of narrowing a deliberative space and reaching decisions should be carried out (Lövbrand et al. 2011, Moore 2017). From a deliberative systems perspective, this narrowing function is assigned to the policy spheres. Though this strategy could obstruct global agreement, it could also empower the public sphere and stimulate more diverse and radical policies from below. Our deliberative systems approach does not designate a particular path forward. Rather, this approach gives perspective to the respective positions and identifies the key tensions and aspects regarding which further exploration is needed.

\section{Concluding remarks}

Based on our analysis of the current research on the IPCC and the different pathways toward democratization, we emphasize three main points, which also suggest where further research is needed. First, there is a need to consider and discuss the ontological and epistemological assumptions underlying the presentation of expert advice. Different fundamental views of science (as a rationalist or a constructivist enterprise) lead to different understandings of how the scientific sphere could and should contribute to the democratization of GEG. We have shown that the different paths of democratization build on, and reproduce, certain ontological assumptions and that it is essential to expose and debate these assumptions and their consequences when discussing the future development of the IPCC and similar bodies. The current central role of consensus is crucial in reproducing the dominating ontology; also crucial is the logic that uncertainties can be enumerated or specified and thus compared, which implies that it is possible to identify how far we are from the truth. The social nature of these practices needs to be further explored and more broadly acknowledged.

Second, the two paths toward democratization that have been outlined emphasize the need to rethink epistemic authority. The predominant understanding is that epistemic authority is achieved through building scientific consensus, which is accomplished by adhering to traditional scientific values (such as precision and control, see Wynne 2003). By creating a unanimous scientific voice, it is possible to speak truth to power and thus (hopefully) have a direct influence on policy making. However, we argue that claims to epistemic authority do not need to be based on this restricted view where science is considered to be superior (cf. Reed 1996). The scientific sphere possesses unique competences in crucial deliberative capacities such as reliability, argumentation and reflexivity, particularly in relation to the generalizability and intrinsic value dimension of claims. Expert deliberation is often considered exemplary deliberative practice (Moore 2017). Deliberative qualities may legitimate science and lend authority to its claims; however, the democratizing potential of these qualities depends on their influence on the deliberative capacity of GEG as a whole.

Finally, a systemic approach to deliberation provides a productive perspective on the "democratization of science" debate. Given its emphasis on deliberative qualities and the deliberative capacity of the entire system, a systemic approach does not demand that a democratization of science follow the same logic as the policy sphere(s) (cf. Lövbrand et al. 2011). What is important is the role that the scientific sphere plays in enabling or inhibiting 
deliberation in the broader society. We have shown that the different paths emphasize different democratizing functions for the IPCC. One single assessment cannot accommodate all these functions in relation to GEG. We have therefore suggested the possibility of having parallel assessments directed at different aspects of climate change and at strengthening different deliberative qualities and democratic functions. Key questions for furthering this debate are how the deliberative qualities fostered in the scientific sphere can be strengthened and how they can gain a broader influence in and beyond the scientific sphere. There is a need to empirically investigate the consequences of a science that expands rather than narrows the deliberative space. We must learn more about the empowering potential of the radical path and its consequences for the decision-making capacity of GEG.

Acknowledgements We thank the anonymous reviewers of an earlier version for their insightful and constructive comments, which have been very helpful for improving the paper.

Open Access This article is distributed under the terms of the Creative Commons Attribution 4.0 International License (http://creativecommons.org/licenses/by/4.0/), which permits unrestricted use, distribution, and reproduction in any medium, provided you give appropriate credit to the original author(s) and the source, provide a link to the Creative Commons license, and indicate if changes were made.

\section{References}

Aylett A (2010) Conflict, collaboration and climate change: participatory democracy and urban environmental struggles in Durban, South Africa. Int J Urban and Reg Research 34(3):478-495

Baber WF, Bartlett RV (2005) Deliberative environmental politics: democracy and ecological rationality. MIT Press, Cambridge, Ma

Beck S (2011) Moving beyond the linear model of expertise? IPCC and the test of adaptation. Reg Environ Chang 11(2):297-306

Beck S (2012) Between tribalism and trust: the IPCC under the "public microscope". Nature and Culture 7(2): $151-173$

Beck S, Borie M, Chilvers J et al (2014) Towards a reflexive turn in the governance of global environmental expertise. The cases of the IPCC and the IPBES. GAIA-Ecol Perspect Sci Soc 23(2):80-87

Berg M, Lidskog R (2017) Deliberative democracy' meets 'democratised science': a deliberative systems approach to global environmental governance. Environ Polit 27(1):1-20

Bijker WE, Bal R, Hendriks R (2009) The paradox of scientific authority: the role of scientific advice in democracies. MIT Press, Cambridge, Ma

Bohman J (2006) Deliberative democracy and the epistemic benefits of diversity. Episteme 3(3):175-191

Brown MB (2015) Politicizing science: conceptions of politics in science and technology studies. Soc Stud Sci 45(1):3-30

Callon M, Barthe Y, Lascoumes P (2009) Acting in an uncertain world. MIT Press, Cambridge, Ma

Carnicer J, Peñuelas J (2012) The world at a crossroads: financial scenarios for sustainability. Energy Policy 48 : 611-617

Christiano T (2012) Rational deliberation among experts and citizens. In: Parkinson J, Mansbridge J (eds) Deliberative systems: deliberative democracy at the large scale. Cambridge UP, Cambridge, pp 27-51

Chambers S (2003) Deliberative democratic theory. Ann Rev Polit Sci 6(1):307-326

Curry J (2011) Reasoning about climate uncertainty. Clim Chang 108(4):723-732

Díaz S, Demissew S, Joly C et al (2015) The IPBES conceptual framework: connecting nature and people. Curr Opin Environ Sustain 14:1-16

Dryzek J (1990) Discursive democracy: politics, policy, and political science. Cambridge UP, Cambridge

Dryzek JS (2006) Deliberative global politics: discourse and democracy in a divided world. Polity, Cambridge

Edenhofer O, Kowarsch M (2015) Cartography of pathways: a new model for environmental policy assessments. Environ Sci Policy 51:56-64

Elstub S (2010) The third generation of deliberative democracy. Polit Stud Rev 8(3):291-307

Esguerra A, Beck S, Lidskog R (2017) Stakeholder engagement in the making: IPBES legitimization politics. Global Environ Polit 17(1):59-76 
Fischer F (2003) Reframing public policy: discursive politics and deliberative practices: discursive politics and deliberative practices. Oxford UP, Oxford

Ford JD, Vanderbilt W, Berrang-Ford L (2012) Authorship in IPCC AR5 and its implications for content: climate change and indigenous populations in WGII. Clim Chang 113(2):201-213

Freudenburg WR, Muselli V (2013) Reexamining climate change debates: scientific disagreement or scientific certainty argumentation methods (SCAMs)? Am Behav Sci 57(6):777-795

Friedrichs J (2011) Peak energy and climate change: the double bind of post-normal science. Futures 43(4):469477

Grundmann R (2006) Ozone and climate: scientific consensus and leadership. Sci Technol Hum Values 31(1): 73-101

Haas P, Stevens C (2011) Organized science, usable knowledge, and multilateral environmental governance. In: Lidskog R, Sundqvist G (eds) Governing the air: the dynamics of science, policy, and citizen interaction. MIT Press, Cambridge, Ma., pp 125-162

Habermas J (1996) Between facts and norms. Polity, London

Hajer MA (2012) A media storm in the world risk society: enacting scientific authority in the IPCC controversy (2009-10). Critical Policy Stud 6(4):452-464

Ho-Lem C, Zerriffi H, Kandlikar M (2011) Who participates in the Intergovernmental Panel on Climate Change and why: a quantitative assessment of the national representation of authors in the Intergovernmental Panel on Climate Change. Glob Environ Chang 21(4):1308-1317

Hulme M (2009) Why we disagree about climate change: understanding controversy, inaction and opportunity. Cambridge UP, Cambridge

Hulme M, Mahoney M (2010) Climate change: what do we know about the IPCC? Prog Phys Geogr 34(5):705-718

IPCC (2017a) IPCC calls for nominations of authors for the Sixth Assessment Report. IPCC Press Release 18 September 2017. 2017/18/PR. http://ipcc.ch/news_and_events/PR-AR6_nominations.shtml

IPCC (2017) Chair's vision paper AR6 Scoping Meeting, Addis Adaba, Ethiopia 1-5 May 2017. IPCC AR6SCOP/Doc.2, (24.IV.2017) http://www.ipcc.ch/apps/eventmanager/documents/46/220520170356-Doc. $\% 202 \% 20-\% 20$ Chair\%20Vision\%20Paper\%20.pdf

IPCC (2017c) Decision, chapter outline of the working group I contribution to the IPCC sixth assessment report (AR6). (10.IX.2017). Agenda Item: 7. Forty-sixth session of the IPCC, Montreal, Canada 6-10 September 2017. http://ipcc.ch/meetings/session46/AR6_WGI_outlines_P46.pdf

Jasanoff S (2010) A new climate for society. Theory Culture Soc 27(2-3):233-253

Jasanoff S (2012) Science and public reasons. Routledge, London

Kvale S (1995) The social construction of validity. Qual Inq 1(1):19-40

Leuschner A (2012) Pluralism and objectivity: exposing and breaking a circle. Stud Hist Philos Sci Part A 43(1): 191-198

Lidskog R, Sundqvist G (2015) When does science matter? International relations meets science and technology studies. Global Environ Polit 15(1):1-20

Löfmarck E, Lidskog R (2017) Bumping against the boundary: IPBES and the knowledge divide. Environ Sci Policy 69:22-28

Lövbrand E, Pielke R, Beck S (2011) A democracy paradox in studies of science and technology. Sci Technol Hum Values 36(4):474-496

Mansbridge J et al (2012) A systemic approach to deliberative democracy. In: Parkinson J, Mansbridge J (eds) Deliberative systems: deliberative democracy at the large scale. Cambridge UP, Cambridge, pp 1-26

Montana J (2017) Accommodating consensus and diversity in environmental knowledge production: achieving closure through typologies in IPBES. Environ Sci Pol 28:20-27

Moore A (2017) Critical elitism. Deliberation, democracy, and the problem of expertise. Cambridge UP, Cambridge

Nowotny H, Scott P, Gibbons M (2001) Re-thinking science. Knowledge and the public in an age of uncertainty. Polity Press, Cambridge

Parkinson J (2012) Democratizing deliberative systems. In: Parkinson J, Mansbridge J (eds) Deliberative systems: deliberative democracy at the large scale. Cambridge Up, Cambridge, pp 151-172

Reed MI (1996) Expert power and control in late modernity: an empirical review and theoretical synthesis. Organ Stud 17(4):573-597

Setälä M (2014) The public sphere as a site of deliberation: an analysis of problems of inclusion. In: Elstub S, McLaverty P (eds) Deliberative democracy_issues and cases. Oxford UP, Oxford, pp 149-165

Siebenhüner B (2003) The changing role of nation states in international environmental assessments - the case of the IPCC. Glob Environ Chang 13(2):113-123

Smith G (2003) Deliberative democracy and the environment. Routledge, London

Stevenson H, Dryzek JS (2014) Democratizing global climate governance. Cambridge UP, Cambridge

Stone D (2012) Policy paradox: the art of political decision making, 3rd edn. WW Norton, New York 
Sundqvist G, Bohlin I, Hermansen EAT, Yearley S (2015) Formalization and separation: a systematic basis for interpreting approaches to summarizing science for climate policy. Soc Stud Sci 45(3):416-440

Swart R, Bernstein L, Ha-Duong M, Petersen A (2009) Agreeing to disagree: uncertainty management in assessing climate change, impacts and responses by the IPCC. Clim Chang 92(1-2):1-29

Thompson DF (2008) Deliberative democratic theory and empirical political science. Annu Rev Polit Sci 11: $497-520$

Turnhout E, Dewulf A, Hulme M (2016) What does policy-relevant global environmental knowledge do? The cases of climate and biodiversity. Curr Opin Environ Sustain 18:65-72

Van Der Sluijs JP (2012) Uncertainty and dissent in climate risk assessment: a post-normal perspective. Nature and Culture, 7(2), 174-195

Van der Sluijs JP, Van Est R, Riphagen M (2010) Beyond consensus: reflections from a democratic perspective on the interaction between climate politics and science. Curr Opin Environ Sustain 2(5):409-415

Warren ME (2012) When, where and why do we need deliberation, voting, and other means of organizing democracy? A problem-based approach to democratic systems. Annual Meeting of the American Political Science Association, August 30 September 2012

Wynne B (2003) Seasick on the third wave? Subverting the hegemony of propositionalism. Soc Stud Sci 33(3): $401-417$

Wynne B (2010) Strange weather, again climate science as political art. Theory, Culture \& Society, 27(2-3), 289305 